\title{
Circulating tumor cells in lung carcinogenesis
}

\author{
Minireview
}

H. SKOVIEROVA ${ }^{1}$, E. VIDOMANOVA ${ }^{1}$, M. SKOVIERA ${ }^{2}$, B. TOTHOVA ${ }^{1}$, E. HALASOVA ${ }^{1,3}$, J. STRNADEL ${ }^{1, *}$

${ }^{1}$ Biomedical Center Martin, Jessenius Faculty of Medicine in Martin, Comenius University in Bratislava, Slovakia; ${ }^{2}$ Lutheran Academy in Martin, Slovakia; ${ }^{3}$ Department of Medical Biology, Jessenius Faculty of Medicine in Martin, Comenius University in Bratislava, Slovakia

${ }^{*}$ Correspondence: jan.strnadel@jfmed.uniba.sk

Received April 30, 2018 / Accepted June 13, 2018

\begin{abstract}
Metastasis development causes death in over $90 \%$ of cancer patients, and understanding the underlying biological features has long been hindered by difficulties in studying the widespread cancerous lesions and the absence of reliable methods of isolating and detecting viable metastatic cells during disease progression. These problems have an adverse impact on developing new agents capable of blocking cancer spread. Circulating tumor cells (CTCs) have a crucial role in carcinogenesis, and this review presents advanced understanding of the characteristics of CTCs and CTC cluster metastatic properties. CTC analysis could well be more valuable for the biomarker profile than tissue biopsies, and herein we highlight current research findings which have the potential to improve clinical management of lung cancer patients. We also discuss problems in CTCs and CTC cluster biology, the limitations of detection methods and possible future diagnostic and therapeutic approaches for the study of circulating cells.
\end{abstract}

Key words: circulating tumor cells (CTCs), CTC clusters, lung cancer, metastases

Circulating tumor cells (CTCs) in the blood stream of cancer patients are regarded as potential metastatic seeds and their detailed characterization could lead to more correct prognosis and better diagnosis and therapy of metastases. CTC clusters are a different type of CTCs, with specific biological properties including higher metastatic potential [1]. Metastasis is a multi-step process where cancer cells detach from the primary tumor and penetrate the blood stream. When CTCs stay in the circulation, they enter distant organs which CTCs may colonise and then proliferate. Until recently, many studies have focused on the end of this process, macroscopic metastases. However, recent advances in technology have enabled the isolation and molecular analysis of the circulating cells, thus detecting the dissemination of cancer cells during tumorigenesis [1].

Epithelial-to-mesenchymal transition (EMT) has a crucial role in the initial steps of dissemination and metastasis development. This is a complex process leading to increased cell motility through degradation of cell-cell contact junctions, loss of cell adhesion, changes in apical-basal polarity and epithelial cell phenotype, thereby promoting cancer metastasis [2]. The reverse process of EMT, mesenchymal-toepithelial transition (MET), is expected to have a fundamental role after CTCs and CTC clusters settle in distant tissues [3]. The de-differentiation processes mediated by EMT/MET are now accepted as hallmarks of cancer [4].

Lung cancer is one of the leading causes of cancer-related mortality worldwide, with more than 1.8 million estimated new cases each year. Despite progression in biomedical research and improvements in both therapeutic options and the diagnostic tools, lung cancer has a five-year overall survival rate of $18 \%$ for all stages [5]. One of the main reasons for this poor outcome is late diagnosis, because a lot of the patients are diagnosed at advanced stages when curative surgery is no longer possible [6]. Therefore, better understanding of the molecular mechanisms underlying lung cancer can open new therapeutic possibilities in specific diagnosis and disease treatment.

In our review, we present the current understanding of metastatic potential of single CTCs together with CTC 
clusters and their mode of dissemination, and finally assess the importance of CTCs as liquid biomarkers for lung cancer management.

\section{Biology of CTCs and CTC clusters}

CTCs (Figure 1) are heterogeneous cancer cell populations that circulate as single cells or as cell clusters in blood and/ or lymphatic vessels. CTCs contain a subpopulation of cells with the metastatic potential and the ability to re-grow to the tumor (termed "tumor self-seeding" or "cross-seeding") [7]. While Thomas Ashworth observed circulating cells for the first time in the blood of a man with metastatic cancer more than 150 years ago, but CTC research was not possible for more than a century because of the lack of appropriate analytic methods. CTC characterization has recently improved with advances in increased sensitivity for isolation and improved detection methods. CTCs do not migrate alone in the circu-

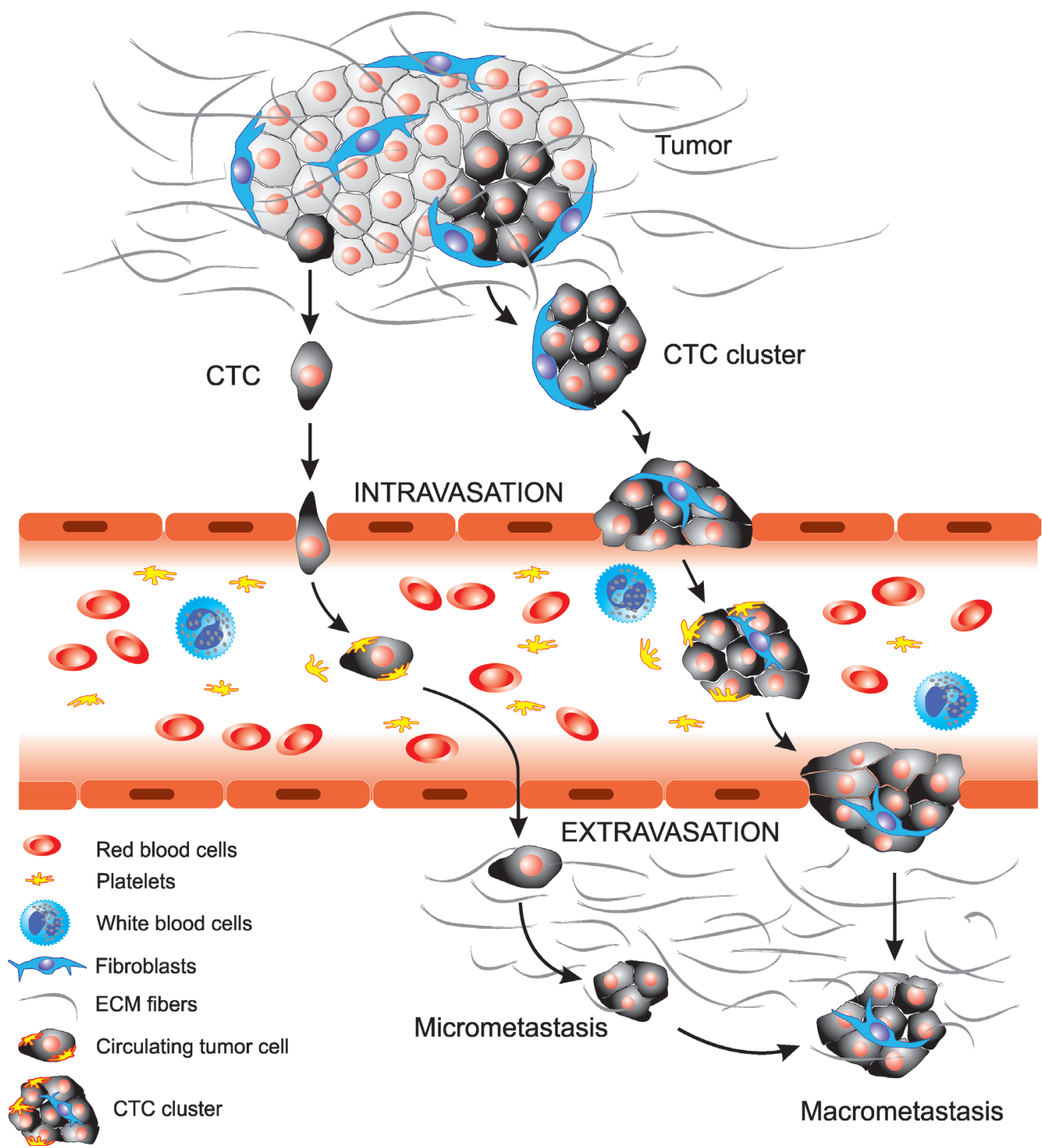

Figure 1. The overview of EMT/MET process in tumor metastasis development. Genetic factors and cancer cell's microenvironment may initiate the malignant transformation through EMT process. Detached tumor cells can enter into the blood or lymphatic vessels (intravasation). When the circulating tumor cells (CTCs) and/or CTC clusters are in the circulation, only a small number of them may survive. The persisting circulating cells can extravasate into the parenchyma at distant side. In this new stromal environment, cancer cells can form micro-metastasis with the ability to proliferate into fully malignant, secondary tumors. 
lation, but with other non-tumor entities, and CTCs are promptly coated by platelets in the circulation. Tumor cellinduced platelet aggregates result in tumor micro-emboli with greater entrapment in small vessels, allowing more time for extravasation to occur. Platelets also promote adhesion to the luminal side of the endothelia through surface molecules, such as selectins [8]. Despite all of this support, CTCs can persist in circulation only for 1-2.4 hours, and most die due to stress or anoikis [9].

CTC clusters (Figure 1) comprise a group of more than two or three cancer cells (up to 100), with strong cell-cell interactions and these are detected in the cancer patient's blood [1]. CTC clusters contain a number of cancer cells with or without non-cancer cells, such as immune, epithelial, and/ or mesenchymal cells, platelets, pericytes and cancerassociated fibroblasts [10]. These non-tumor components help tumor cells survive and metastasize in various ways. For example, the tumor-derived stromal cells, such as fibroblasts, endothelial or tumor-infiltrated myeloid cells can increase the viability of cancer cells in CTC clusters, and promote metastases. It was shown that depletion of the cancer-associated fibroblasts in CTC clusters significantly decreases the number of metastases [11].

Based on metastasis integrity, another type of tumor cells is important in this process. Dormant tumor cells may "sleep" for long time before regrowth and these can remain in the distant tissue as a micro-metastasis. Dormant tumor cells were also found in the bone marrow where they mobilize to secondary sites before activation of cell proliferation [12]. Due to the lack of specific molecular markers for detection of dormant cells at distant sites in mouse tumor models and cancer patients, our current understanding of tumor dormancy is largely based on metastases isolated from bone marrow [13]. However, further studies are needed to better understand the involvement of EMT process in the tumor cell dormancy.

Analysis of CTCs and CTC clusters permits study of human cancer cells that have obtained invasive and migratory activities. The presence of circulating cells in breast, colorectal, lung, pancreatic, and prostate cancer patients has been proven to be a bad prognostic factor which supports tumor cell invasion and dissemination during metastatic progression and leads to poor clinical outcome [14-16]. The EMT plasticity in metastases was studied in various CTCs models, such as in vitro cell lines and in vivo animals and human patients. Co-expression of both, epithelial and mesenchymal genes in circulating clusters was proven in several types of cancer. However, the corresponding primary tumors very rarely co-express both types of genes $[4,17]$.

\section{Metastatic activity of CTCs and CTC clusters}

Before tumor cells start to metastasize, they must overcome anoikis, a form of programmed cell death which is initiated when anchorage-dependent cells start to detach from their surrounding extracellular matrix (ECM) [18]. Many cell culture and animal tumor model studies have shown the importance of EMT in metastasis initiation. However, the EMT process is difficult to identify in some human cancer types, since cancer cells undergoing transition share similar molecular and morphological features with surrounding stromal fibroblasts [13, Strnádel unpublished data].

How can tumor cells migrate from their primary tissue? One of the most common theories is that cancer cells in solid tumors must undergo the EMT process in order to invade. This phenotypic transition is followed by several molecular changes during which epithelial cells become more invasive, motile and able to seed at distant sites [19]. It was shown that cells undergoing EMT have down-regulated E-cadherin expression which is one of the features for detachment from neighboring epithelial cells. Due to the complexity of the EMT process, special transcription factors and signaling pathways are activated in epithelial cells to orchestrate all the morphological and molecular changes [20]. Moreover, the activity of matrix metallo-proteinases (MMPs) is increased which helps the degradation of the local ECM and entry into micro-vasculature (Figure 1) [19]. If the EMT process is necessary for dissemination, then MET may be needed for CTCs seeding and their growth in distant tissues. After extravasation, autocrine signalling in a cluster may facilitate more rapid adaptation to a new environment in distant organs. CTC clusters can contain normal cells from the primary site, as in stromal cells; and this has major implications for the "seed and soil" hypothesis. It means that CTC clusters bring their own 'soil' which increases the ability of seeding at distant sites [21].

Inhibition of the EMT process should increase the efficiency of traditional therapy in the experimental setting of lung, hepatic and pancreatic cancer cells [22]. Interestingly, the EMT process in CTCs is unstable and can undergo dramatic changes during therapeutic response. Moreover, CTC clusters have been shown to express more mesenchymal markers in patients after anti-cancer therapy and the dynamic changes during cancer progression [23]. It appears that CTC cluster phenotype is a combination of epithelial and mesenchymal features which reveal cluster plasticity. The combination of mesenchymal motility with survival and dissemination advantages brought by preserving cell-cell junctions enables CTC clusters to gain increased metastatic potential compared to single tumor cells [1].

It was recently shown that CTC clusters have 23-50 times higher metastatic potential than single CTCs and are responsible for almost $97 \%$ of metastases in mouse breast cancer models. Moreover, it was proven that CTC clusters begin as cohesive groups of cells actively separated from the primary tumor and able to collectively migrate into the circulation, instead of passive shedding clumps which originate from aggregating cancer cells in the blood stream $[10,24]$.

Interestingly, it was also discovered that CTC clusters with less than twenty cells could re-organize into single chain-like 
geometries and reduced their hydrodynamic resistance which allows cluster-pass via small vessels [25]. The shape of CTC clusters is highly plastic and cells can be easily re-organize back to a sphere-like shape after passing through capillaries. These observations improve our knowledge of CTC cluster flexibility during metastasis development [25].

Although highly aggressive tumors spread thousands of tumor cells into the blood stream each day, the circulating tumor cells (CTCs) are a fairly rare population in the blood [21]; one circulating tumor cell per $10^{5}-10^{7}$ mononuclear cells was detected in peripheral blood. CTC clusters are even rarer, with only about $3 \%$ of circulating cells [10]. To detect the circulating cells in blood, their fraction could be enriched prior to isolation. Recently, numerous studies have focused on developing suitable methods to identify and enrich CTCs in the circulation [1].

\section{CTCs and CTC clusters in lung cancer}

Non-small cell lung cancer (NSCLC) accounts for about $75-80 \%$ of all lung cancers [5]. Despite improved diagnostic techniques, the great majority of NSCLC patients (70\%) present advanced stage tumors at diagnosis, and there is a 5-year survival rate of less than 5\% [26]. Small cell lung cancer (SCLC) is an aggressive and rapidly growing type of cancer and is a major cause of cancer mortality; with little progress in therapy in the last decades [27]. Development and progression of SCLC is associated with heavy tobacco exposure and there is indirect evidence of the induction of epithelial-to-mesenchymal transition phenotype (EMT) in normal lung and transformed cells. Various groups of active compounds were found in cigarette smoke, such as polycyclic aromatic hydrocarbons, nicotine-derived nitrosamine ketone, and reactive oxygen species which can induce the EMT process through different signaling pathways linked to biological responses to cigarette smoke These include hypoxia, inflammation and oxidative damage [28]. EMT was increased in human bronchial epithelial cells of patient with chronic obstructive pulmonary disease (COPD) [29]. The coexistence of COPD and lung cancer is commonly detected in smokers, and the risk of developing lung cancer in smoking patients is significantly increased in the presence of COPD [30].

Recently, some studies also showed that the analysis of lung CTCs can be used to monitor evolving tumor phenotype in some patients.

These circulating tumor cells (CTCs) have been studied in NSCLC and results reveal that they occur individually or in clusters, and most are negative for the Ki67 proliferation marker [31, 32]. Lindsay, et al. (2017) evaluated CTC prognostic value based on their number, phenotype and molecular profiling in patients with advanced NSCLC [33] and found that more than five CTCs per $10 \mathrm{ml}$ of blood was an independent factor associated with lower overall survival.
The CTCs in SCLC were also detected singly or in clusters which avoid anoikis and these have increased resistance to cytotoxic drugs. Their number directly correlates with decreased overall survival. More specifically, patients with more than fifty CTCs per $7.5 \mathrm{~mL}$ blood have an overall survival of 5.4 months compared to 11.5 months in patients with a lower blood concentration [34]. However, some studies also revealed that CTCs were not detectable in $15-70 \%$ of lung cancer patients $[7,35]$. Further, the detection of CTCs in SCLS patients before and after treatment initiation and also at clinical relapse was associated with worse overall survival [36-38]. Besides, Hou, et al. (2012) then proved that the presence of CTC clusters was associated with worse clinical outcome in these patients [39].

In contrast to the continuously increasing five-year survival rates from breast, colon and rectal cancers, the therapeutic options for SCLC have remained unchanged for decades [40]. Eligibility for appropriate therapy relies on tumor biopsy results, but this invasive procedure itself is associated with relatively high risk of morbidity, and inoperable patients may be omitted from potentially more efficient therapies. For most advanced cancer patients, testing is often limited by insufficient tissue and therefore non-invasive and alternative diagnostic evaluations are required [41]. Identification of novel prognostic and predictive factors remains a top priority, and the application of non-invasive liquid biopsy is a promising tool for identifying biomarkers such as plasma circulating cell-free DNA, microRNA and CTCs.

Here, circulating cell-free microRNA and encapsulated exosome microRNA are emerging biomarkers, but they are still far from becoming clinically useful [42, 43]. Great effort is now focused on isolating and quantifying the plasma circulating cell-free DNA and CTCs in order to improve cancer diagnosisand prognosis and to monitor treatment efficacy [44].

The presence of cancer progenitor cells (less differentiated type of cancer cells) in tumor and in CTC clusters as well as the presence of progenitor CTCs in circulation might be other possible reason for relapse $[45,46]$. Some of clinical studies showed that combination of traditional chemotherapy with epigenetic drugs could be a powerful treatment model to reduce relapse in different types of cancer [47]. However, more clinical and research studies are needed to better understand the mechanisms of epigenetic therapies. It is known that hypermethylation of several genes is likely linked with tumor development [48]. It has been revealed that the combination of DNA methyltransferase inhibitors and histone deacetylase inhibitors can be a promising direction in the treatment of myelodysplastic syndrome [47].

There are almost 400 studies registered on "ClinicalTrials. gov" focused on CTCs in lung cancer, but despite the effort, these circulating cells are still not used in routine clinical practice. This can be explained by low sensitivity of methods for CTCs detection, and also by the difficulty of selecting the reliable lung CTC marker(s). Even though the research is focused on the metastasis development trying to improve 
lung cancer treatment, the analytical specificity and clinical outcome of diagnostic methods must be analyzed in prospective studies in order to obtain the data required for their introduction and use in the daily management of lung cancer patients $[49,50]$. Liquid biopsy could have a great potential for the treatment not only of lung cancer patients. Regardless the numerous techniques and experimental approaches that have been established in this field, the common objective of all of them is to develop a specific, sensitive, and prognostic system to minimize the use of invasive samples which can be translated into the clinical practice [6].

\section{Future perspectives}

In the last twenty years, intense effort has focused on research of the epithelial-to-mesenchymal transition process (EMT) and its involvement in metastasis development via CTCs and CTC clusters. Some of the studies performed on cancer cell lines, animal tumor models and human tumor samples strongly support the hypothesis that the EMT/MET process is important in effective metastatic development. In contrast, some studies failed to detect certain EMT factors in disseminating tumor cells during the EMT process and certain carcinoma cells can disseminate and metastasize without undergoing this EMT process [51]. Although CTC and CTC cluster detection failed in cancer patients, the presence of EMT process during dissemination cannot be excluded, especially due to the lack or limitation of current detection methods. Future research should concentrate on increasing the sensitivity of isolation processes, specificity in the diagnosis of circulating cells with malignant features and the suitability for downstream molecular analysis.

There are still some open questions on CTC and CTC cluster biology; Examples include (1) understanding the molecular mechanisms in CTC clusters formation and new information in the biology of primary cancer cells from which the CTCs were released, (2) investigation of biological pathways of CTC cluster penetration and migration into blood stream, and also metastasis development at distant tissues, (3) improvement in the standardized method for CTCs or CTC clusters isolation which sustain their morphological and molecular characteristics, and (4) the generation of a panel of surface markers which could identify the heterogeneous populations of CTCs to improve the detection of cancer cells in circulation.

To find the solution of these problems would open new fields in CTCs and CTC clusters study and possible future diagnostic and therapeutic approaches [1]. CTCs could present a non-invasive and accessible surrogate source that allows access to biomarker assessment in vulnerable cancer patients for whom tissue biopsies are inaccessible or extremely difficult to perform and to repeat. Moreover, the request for new biomarkers, such as transcriptomic EMT signature from CTCs or CTC clusters compared to primary tumor cells can help us understand the treatment response and might improve prognostication and new therapy. In addition, study of the mechanisms responsible for induction of cell dormancy may open new possibilities of inhibiting regulators during dormancy status, and analysis of the dormant niche using metabolomics and mass spectrometry can identify metabolites and proteins involved in the induction and activation of cancer cell dormancy [52].

CTCs analysis has not been approved in routine clinical practice; perhaps due to the absence of clinical utility. Large-scale ongoing studies, especially in breast cancer, may demonstrate if detection of CTCs and CTC clusters could change clinical practice and lead to future development of new anti-cancer strategy.

Liquid biopsy could also increase the sensitivity in detecting circulating cells and improve monitoring of treatment response, cancer screening and CTC application [53]. Moreover, development of CTC-derived xenografts would be another possibility for CTCs research that leads to drug screening [41]. Concentration on lung metastases, CTCs and plasma cell tumor DNA originating from the primary tumor and different metastatic sites could also provide more information on the source of various biomarkers than tissue biopsies taken at a given time [54], and these could have roles as predictive markers of chemotherapy efficacy.

This hypothesis may support the assumption that plasma cell tumor DNA and CTCs can be used as independent prognostic markers because of their different mechanisms of release from the primary tumor into the circulation. Plasma cell tumor DNA is mainly released by a passive mechanism during cancer cell death, whereas CTCs and CTC clusters can be spread through active processes, including metastases development. Finally, this could lead to improvement in cancer patient quality of life, with the important accent on development of personalized medicine.

Acknowledgements: This work was supported by following grants: Slovak Scientific Grant Agency (VEGA 1/0178/17), Research and Development Support Agency (APVV-15-0217), and the project "Biomedical Center Martin", ITMS code 26220220187, co-financed from EU sources.

\section{References}

[1] FABISIEWICZ A, GRZYBOWSKA E. CTC clusters in cancer progression and metastasis. Med Oncol 2017; 34: 12. https://doi.org/10.1007/s12032-016-0875-0

[2] NIETO MA. Epithelial plasticity: a common theme in embryonic and cancer cells. Science 2013; 342: 1234850. https:// doi.org/10.1126/science. 1234850

[3] ALIX-PANABIERES C, MADER S, PANTEL K. Epithelialmesenchymal plasticity in circulating tumor cells. J Mol Med (Berl) 2017; 95: 133-142. https://doi.org/10.1007/s00109016-1500-6

[4] YEUNG KT, YANG J. Epithelial-mesenchymal transition in tumor metastasis. Mol Oncol 2017; 11: 28-39. https://doi. org/10.1002/1878-0261.12017 
[5] SIEGEL RL, MILLER KD, JEMAL A. Cancer Statistics, 2017. CA Cancer J Clin 2017; 67: 7-30. https://doi.org/10.3322/ caac. 21387

[6] CALABUIG-FARINAS S, JANTUS-LEWINTRE E, HERREROS-POMARES A, CAMPS C. Circulating tumor cells versus circulating tumor DNA in lung cancer-which one will win? Transl Lung Cancer Res 2016; 5: 466-482. https://doi. org/10.21037/tlcr.2016.10.02

[7] ANSARI J, YUN JW, KOMPELLI AR, MOUFARREJ YE, ALEXANDER JS et al. The liquid biopsy in lung cancer. Genes Cancer 2016; 7: 355-367. https://doi.org/10.18632/ genesandcancer.127

[8] LAUBLI H, BORSIG L. Selectins promote tumor metastasis. Semin Cancer Biol 2010; 20: 169-177. https://doi. org/10.1016/j.semcancer.2010.04.005

[9] VANHARANTA S, MASSAGUE J. Origins of metastatic traits. Cancer Cell 2013; 24: 410-421. https://doi. org/10.1016/j.ccr.2013.09.007

[10] ACETO N, BARDIA A, MIYAMOTO DT, DONALDSON MC, WITTNER BS et al. Circulating tumor cell clusters are oligoclonal precursors of breast cancer metastasis. Cell 2014; 158: 1110-1122. https://doi.org/10.1016/j.cell.2014.07.013

[11] HONG Y, FANG F, ZHANG Q. Circulating tumor cell clusters: What we know and what we expect (Review). Int J Oncol 2016; 49: 2206-2216. https://doi.org/10.3892/ ijo.2016.3747

[12] HEDLEY BD, CHAMBERS AF. Tumor dormancy and metastasis. Adv Cancer Res 2009; 102: 67-101. https://doi. org/10.1016/S0065-230X(09)02003-X

[13] TSAI JH, YANG J. Epithelial-mesenchymal plasticity in carcinoma metastasis. Genes Dev 2013; 27: 2192-2206. https:// doi.org/10.1101/gad.225334.113

[14] CRISTOFANILLI M, BUDD GT, ELLIS MJ, STOPECK A, MATERA J et al. Circulating tumor cells, disease progression, and survival in metastatic breast cancer. $\mathrm{N}$ Engl J Med 2004; 351: 781-791. https://doi.org/10.1056/NEJMoa040766

[15] HAN L, CHEN W, ZHAO Q. Prognostic value of circulating tumor cells in patients with pancreatic cancer: a meta-analysis. Tumor Biol 2014; 35: 2473-2480. https://doi.org/10.1007/ s13277-013-1327-5

[16] WEISMANN P, WEISMANOVA E, MASAK L, MLADA $\mathrm{K}$, KEDER $\mathrm{D}$ et al. The detection of circulating tumor cells expressing E6/E7 HR-HPV oncogenes in peripheral blood in cervical cancer patients after radical hysterectomy. Neoplasma 2009; 56: 230-238. https://doi.org/10.4149/ neo_2009_03_230

[17] WU S, LIU S, LIU Z, HUANG J, PU X et al. Classification of circulating tumor cells by epithelial-mesenchymal transition markers. PLoS One 2015; 10: e0123976. https://doi. org/10.1371/journal.pone.0123976

[18] HEERBOTH S, HOUSMAN G, LEARY M, LONGACRE M, BYLER $S$ et al. EMT and tumor metastasis. Clin Transl Med 2015; 4: 6. https://doi.org/10.1186/s40169-015-0048-3

[19] JOOSSE SA, GORGES TM, PANTEL K. Biology, detection, and clinical implications of circulating tumor cells. EMBO Mol Med 2015; 7: 1-11. https://doi.org/10.15252/ emmm.201303698
[20] SKOVIEROVA H, OKAJCEKOVA T, STRNADEL J, VIDOMANOVA E, HALASOVA E. Molecular regulation of epithelial-to-mesenchymal transition in tumorigenesis (Review). Int J Mol Med 2018; 41: 1187-1200. https://doi. org/10.3892/ijmm.2017.3320

[21] DASGUPTA A, LIM AR, GHAJAR CM. Circulating and disseminated tumor cells: harbingers or initiators of metastasis? Mol Oncol 2017; 11: 40-61. https://doi.org/10.1002/18780261.12022

[22] THIERY JP, ACLOQUE H, HUANG RY, NIETO MA. Epithelial-mesenchymal transitions in development and disease. Cell 2009; 139: 871-890. https://doi.org/10.1016/j. cell.2009.11.007

[23] ACETO N, TONER M, MAHESWARAN S, HABER DA. En route to metastasis: circulating tumor cell cluster and epithelial-to-mesenchymal transition. Trends Cancer 2015; 1: 44-52. https://doi.org/10.1016/j.trecan.2015.07.006

[24] CHEUNG KJ, PADMANABAN V, SILVESTRI V, SCHIPPER K, COHEN JD et al. Polyclonal breast cancer metastases arise from collective dissemination of keratin 14-expressing tumor cell clusters. Proc Natl Acad Sci USA 2016; 113: E854863. https://doi.org/10.1073/pnas.1508541113

[25] AU SH, STOREY BD, MOORE JC, TANG Q, CHEN YL et al. Clusters of circulating tumor cells traverse capillarysized vessels. Proc Natl Acad Sci USA 2016; 113: 4947-4952. https://doi.org/10.1073/pnas.1524448113

[26] COCO S, ALAMA A, VANNI I, FONTANA V, GENOVA $\mathrm{C}$ et al. Circulating Cell-Free DNA and Circulating Tumor Cells as Prognostic and Predictive Biomarkers in Advanced Non-Small Cell Lung Cancer Patients Treated with FirstLine Chemotherapy. Int J Mol Sci 2017; 18. https://doi. org/10.3390/ijms18051035

[27] HAMILTON G, RATH B. Mesenchymal-Epithelial Transition and Circulating Tumor Cells in Small Cell Lung Cancer. Adv Exp Med Biol 2017; 994: 229-245. https://doi. org/10.1007/978-3-319-55947-6_12

[28] VU T, JIN L, DATTA PK. Effect of Cigarette Smoking on Epithelial to Mesenchymal Transition (EMT) in Lung Cancer. J Clin Med 2016; 5. https://doi.org/10.3390/jcm5040044

[29] MILARA J, PEIRÓ T, SERRANO A, CORTIJO J. Epithelial to mesenchymal transition is increased in patients with COPD and induced by cigarette smoke. Thorax 2013; 68: 410-420. https://doi.org/10.1136/thoraxjnl-2012-201761

[30] SOHAL SS, WARD C, WALTERS EH. Importance of epithelial mesenchymal transition (EMT) in COPD and asthma. Thorax 2014; 69: 768. https://doi.org/10.1136/thoraxjnl-2014-205582

[31] HALASOVA E, ADAMKOV M, MATAKOVA T, VYBOHOVA D, ANTOSOVA M et al. Expression of Ki-67, Bcl-2, Survivin and 553 Proteins in Patients with Pulmonary Carcinoma. Adv Exp Med Biol 2013; 756: 15-21. https://doi. org/10.1007/978-94-007-4549-0_3

[32] KREBS MG, HOU JM, SLOANE R, LANCASHIRE L, PRIEST L et al. Analysis of circulating tumor cells in patients with non-small cell lung cancer using epithelial marker-dependent and -independent approaches. J Thorac Oncol 2012; 7: 306-315. https://doi.org/10.1097/JTO.0b013e31823c5c16 
[33] LINDSAY CR, FAUGEROUX V, MICHIELS S, PAILLER E, FACCHINETTI F et al. A prospective examination of circulating tumor cell profiles in non-small-cell lung cancer molecular subgroups. Ann Oncol 2017; 28: 1523-1531. https:// doi.org/10.1093/annonc/mdx15

[34] GKOUNTELA S, SZCZERBA B, DONATO C, ACETO N. Recent advances in the biology of human circulating tumor cells and metastasis. ESMO Open 2016; 1: e000078. https:// doi.org/10.1136/esmoopen-2016-000078

[35] XU Q, ZHU Y, BAI Y, WEI X, ZHENG X et al. Detection of epidermal growth factor receptor mutation in lung cancer by droplet digital polymerase chain reaction. Onco Targets Ther 2015; 8: 1533-1541. https://doi.org/10.2147/OTT.S84938

[36] HUANG CH, WICK JA, SITTAMPALAM GS, NIRMALANANDHAN VS, GANTI AK et al. A multicenter pilot study examining the role of circulating tumor cells as a blood-based tumor marker in patients with extensive small-cell lung cancer. Front Oncol 2014; 4: 271. https://doi.org/10.3389/ fonc.2014.00271

[37] IGAWA S, GOHDA K, FUKUI T, RYUGE S, OTANI S et al. Circulating tumor cells as a prognostic factor in patients with small cell lung cancer. Oncol Lett 2014; 7: 1469-1473. https://doi.org/10.3892/ol.2014.1940

[38] MESSARITAKIS I, POLITAKI E, KOTSAKIS A, DERMITZAKI EK, KOINIS F et al. Phenotypic characterization of circulating tumor cells in the peripheral blood of patients with small cell lung cancer. PLoS One 2017; 12: e0181211. https://doi.org/10.1371/journal.pone.0181211

[39] HOU JM, KREBS MG, LANCASHIRE L, SLOANE R, BACKEN A et al. Clinical significance and molecular characteristics of circulating tumor cells and circulating tumor microemboli in patients with small-cell lung cancer. J Clin Oncol 2012; 30: 525-532. https://doi.org/10.1200/ JCO.2010.33.3716

[40] COLEMAN MP, ALLEMANI C. Cancer: the elephant in the room. Lancet 2015; 385: 1047-1048. https://doi.org/10.1016/ S0140-6736(15)60571-2

[41] ILIE M, SZAFER-GLUSMAN E, HOFMAN V, LONG-MIRA E, SUTTMANN R et al. Expression of MET in circulating tumor cells correlates with expression in tumor tissue from advanced-stage lung cancer patients. Oncotarget 2017; 8: 26112-26121. https://doi.org/10.18632/oncotarget.15345

[42] INAMURA K, ISHIKAWA Y. MicroRNA In Lung Cancer: Novel Biomarkers and Potential Tools for Treatment. J Clin Med 2016; 5. https://doi.org/10.3390/jcm5030036

[43] VANNI I, ALAMA A, GROSSI F, DAL BELLO MG, COCO S. Exosomes: a new horizon in lung cancer. Drug Discov Today 2017; 22: 927-936. https://doi.org/10.1016/j. drudis.2017.03.004
[44] GOLD B, CANKOVIC M, FURTADO LV, MEIER F, GOCKE CD. Do circulating tumor cells, exosomes, and circulating tumor nucleic acids have clinical utility? A report of the association for molecular pathology. J Mol Diagn 2015; 17: 209-224. https://doi.org/10.1016/j.jmoldx.2015.02.001

[45] KIM YN, KOO KH, SUNG JY, YUN UJ, KIM H. Anoikis resistance: an essential prerequisite for tumor metastasis. Int J Cell Biol 2012; 2012: 306879. https://doi. org/10.1155/2012/306879

[46] SARKAR S, HORN G, MOULTON K, OZA A, BYLER S et al. Cancer development, progression, and therapy: an epigenetic overview. Int J Mol Sci 2013; 14: 21087-21113. https://doi.org/10.3390/ijms141021087

[47] DAMASKOS C, VALSAMI S, KONTOS M, SPARTALIS E, KALAMPOKAS T et al. Histone Deacetylase Inhibitors: An Attractive Therapeutic Strategy Against Breast Cancer. Anticancer Res 2017; 37: 35-46. https://doi.org/10.21873/anticanres. 11286

[48] SKOVIEROVA H, VIDOMANOVA E, MAHMOOD S, SOPKOVAÁ J, DRGOVA A et al. The Molecular and Cellular Effect of Homocysteine Metabolism Imbalance on $\mathrm{Hu}$ man Health. Int J Mol Sci 2016; 17. https://doi.org/10.3390/ ijms17101733

[49] KRUTAKOVA M, SARLINOVA M, MATAKOVA T, DZIAN A, HAMZIK J et al. The Role of Dysregulated MicroRNA Expression in Lung Cancer. Adv Exp Med Biol 2016; 911: 1-8. https://doi.org/10.1007/5584_2016_219

[50] SARLINOVA M, MAJEROVA L, MATAKOVA T, MUSAK L, SLOVAKOVA P et al Polymorphisms of DNA repair genes and lung cancer in chromium exposure. Adv Exp Med Biol 2015; 833: 1-8. https://doi.org/10.1007/5584_2014_82

[51] SARKAR FH, LI Y, WANG Z, KONG D. Pancreatic cancer stem cells and EMT in drug resistance and metastasis. Minerva Chir 2009; 64: 489-500.

[52] GHAJAR CM. Metastasis prevention by targeting the dormant niche. Nat Rev Cancer 2015; 15: 238-247. https://doi. org/10.1038/nrc3910

[53] CABEL L, PROUDHON C, GORTAIS H, LOIRAT D, COUSSY $\mathrm{F}$ et al. Circulating tumor cells: clinical validity and utility. Int J Clin Oncol 2017; 22: 421-430. https://doi. org/10.1007/s10147-017-1105-2

[54] PAILLER E, ADAM J, BARTHELEMY A, OULHEN M, AUGER N et al. Detection of circulating tumor cells harboring a unique ALK rearrangement in ALK-positive non-small-cell lung cancer. J Clin Oncol 2013; 31: 2273-2281. https://doi. org/10.1200/JCO.2012.44.5932 